\title{
Vascular endothelial growth factor and soluble intercellular adhesion molecule-1 in lung adenocarcinoma with malignant pleural effusion: Correlations with patient survival and pleural effusion control
}

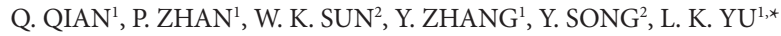 \\ ${ }^{1}$ First Department of Respiratory Medicine, Nanjing Chest Hospital, 215 Guangzhou Road, Nanjing 210029, China; ${ }^{2}$ Department of Respiratory \\ Medicine, Jinling Hospital, 305 East Zhongshan Road, Nanjing 210002, China \\ *Correspondence: yulike_nanjing@163.com
}

Received December 17, 2011 / Accepted February 22, 2012

\begin{abstract}
The mechanisms by which vascular endothelial growth factor (VEGF) and soluble intercellular adhesion molecule-1 (sICAM-1) contribute to lung cancer growth have not been fully elucidated. This study aimed to assess the role of VEGF and sICAM-1 in control of pleural effusions (PE) and survival in patients with primary human lung adenocarcinoma.

Using enzyme-linked immunoadsorbent assay, the concentrations of VEGF and sICAM-1 were measured in pleural effusions and serum from a total of 79 lung adenocarcinoma patients with malignant pleural effusions (MPE) and 24 patients with tuberculosis. Data were correlated with the efficacy of MPE control and survival.

Compared to patients with tuberculosis, the levels of VEGF and sICAM-1 in both PE and serum were significantly higher in patients with lung adenocarcinoma. Statistically significant correlation was observed between PE VEGF levels and MPE control. PE VEGF $\geq 2760 \mathrm{pg} / \mathrm{ml}$ was used as a cut-off point for failure to MPE control (odds ratio=7.06; 95\% confidence interval (CI), 2.40-20.78; $<<0.001$ ). The median progression-free survival (PFS) from response assessment was 3 months. In a multivariate analysis, PE VEGF (hazard ratio [HR], 1.16; 95\% CI, 1.02-1.32), serum sICAM-1 (HR, 1.90; 95\% CI, 1.17-3.07) were confirmed as independent prognostic factors for PFS.

The levels of VEGF in PE can be used to predict the therapeutic efficacy in the control of MPE and this, together with serum level of sICAM-1 is potential survival factors in lung adenocarcinoma patients with MPE.
\end{abstract}

Key words: vascular endothelial growth factor, soluble intercellular adhesion molecule-1, malignant pleural effusion, lung adenocarcinoma, survival

Malignant pleural effusion (MPE) represents a common (500 new cases/million population/yr) clinical presentation predominantly found in patients with lung adenocarcinoma $[1,2]$. The presence of MPE is an important sign of recurrent or advanced malignancies and has short life expectancy $[3,4]$. In spite of its frequent occurrence in clinical situation, limited studies have been reported on the management of MPE and patients in general have little improvement from available therapies. Thus, understanding of the molecular mechanisms of MPE pathophysiology is important and may provide more safer and effective therapeutic options.

Study of the molecular mechanisms of MPE have found that new blood vessel formation (angiogenesis) and increased permeability of existing and newly formed blood vessels are important in the development of MPE [5]. The vascular en- dothelial growth factor (VEGF) pathway is critical in tumor angiogenesis and becomes an important therapeutic target. The VEGF family, by binding to their cognate tyrosine kinase receptors, stimulates endothelial cell proliferation and migration, increases permeability of existing blood vessels in the tumor microenvironment [6]. Several lines of evidence suggest that expression of VEGF in peripheral lung tumors is important in the development of MPE $[7,8]$.

Elevated serum or plasma concentrations of soluble intercellular adhesion molecule-1(sICAM-1) have been reported in patients with several human malignancies $[9,10]$ and the presence of sICAM-1 correlated with tumor progression and metastasis [11-13]. In non-small cell lung cancer patients, increased level of sICAM-1 was correlated with the patient short survival and poor response to chemotherapy [14]. One 
of the underlying mechanisms is that sICAM-1 can bind to circulating cytotoxic lymphocytes, thereby helping tumors to escape immune recognition. In addition, sICAM-1 may act as an angiogenic factor to promote angiogenesis and stimulate tumor cell growth $[15,16]$ Nevertheless, the role of sICAM1 in the development of MPE has not been fully studied. Because the poor survival of lung adenocarcinoma patients with MPE, we thereby examined the role of sICAM-1 in this malignancies.

Treatment decisions in routine practice depended mainly on awareness of main prognostic determinants. For MPE patients, evacuation of the pleural fluid, prevention of reaccumulation and prolong survival are the main goals of management [17-19]. In the current study, we focused on these two important factors to determine the possible role in the clinical outcomes of patient survival and MPE control.

\section{Patients and methods}

Patients. The PE and serum samples from two different groups of patients were collected. The first group was com-

Table 1. Lung adenocarcinoma patients Characteristics.

\begin{tabular}{|c|c|c|}
\hline Variable & No.of patients & $\%$ \\
\hline $\begin{array}{l}\text { Characteristic of lung adenocarcinoma } \\
\text { patients }\end{array}$ & 79 & \\
\hline \multicolumn{3}{|l|}{ Gender } \\
\hline Men & 48 & 61 \\
\hline Women & 31 & 39 \\
\hline \multicolumn{3}{|l|}{ age, $y$} \\
\hline$<65$ & 34 & 43 \\
\hline$\geq 65$ & 45 & 56 \\
\hline \multicolumn{3}{|l|}{ Smoking history } \\
\hline never smoker & 33 & 42 \\
\hline former smoker & 24 & 30 \\
\hline smoker & 22 & 28 \\
\hline \multicolumn{3}{|l|}{ Stage } \\
\hline M1a & 55 & 70 \\
\hline M1b & 24 & 30 \\
\hline \multicolumn{3}{|l|}{ ECOG PS } \\
\hline 0 & 37 & 47 \\
\hline 1 & 33 & 42 \\
\hline 2 & 9 & 11 \\
\hline Characteristic of tuberculosis patients & 24 & \\
\hline \multicolumn{3}{|l|}{ Gender } \\
\hline Men & 19 & 79 \\
\hline Women & 5 & 21 \\
\hline \multicolumn{3}{|l|}{ age, y } \\
\hline$<65$ & 20 & 83 \\
\hline$\geq 65$ & 4 & 17 \\
\hline \multicolumn{3}{|l|}{ Smoking history } \\
\hline never smoker & 7 & 29 \\
\hline former smoker & 12 & 50 \\
\hline smoker & 5 & 21 \\
\hline
\end{tabular}

ECOG PS: Eastern Cooperative Oncology Group performance status prised of tuberculosis patients with PE $(n=24)$. The diagnosis of TB was based on a positive culture from the PE or a pleural biopsy. The second group were patients with MPE-associated lung adenocarcinoma $(n=79)$. Patients with previously untreated lung adenocarcinoma with MPE were enrolled prospectively into this study at two institutions (Nanjing Chest Hospital and Jinling Hospital, Nanjing, China) between January 2009 and July 2010. To be eligible for MPE-associated lung adenocarcinoma, patients were verified by cytological analysis or a pleural biopsy; an Eastern Cooperative Oncology Group performance status (PS) from 0 to 2; normal hepatic, renal, and hematologic function and no concomitant serious comorbidities were found.

Eligible patients were initially performed therapeutic thoracocentesis. Chemical pleurodesis was attempted after completed expansion of the lung followed by pleural fluid evacuation with no evidence of trapped lung. The pleurodesing agent was bleomycin. At the same time, at least two cycles of cisplatin and gemcitabine combination chemotherapy was repeated every 3 weeks.

The treatment response of malignant effusion was evaluated according to the following criteria: (1) complete response, no fluid reaccumulation and patients were free of symptoms for at least 4 weeks as determined by chest radiography, ultrasonography and/or CT scan and clinical evaluation; (2) partial response, recurrence of effusion to less than $50 \%$ of the original effusion volume, patients were asymptomatic and no need for thoracentesis for symptom relief within 4 weeks after treatment; (3) failure to response, recurrence of effusion greater than $50 \%$ of the original volume, patients were symptomatic and need for thoracentesis to relieve symptoms within 4 weeks of treatment. Objective response of malignant effusion included complete response and partial response [21]

The study protocol was approved by Jinling Hospital Medical Ethical Committee. All patients provided written informed consent before study-related procedures were performed.

Methods. Specimens of peripheral blood and effusions were collected before pleurodesis and chemotherapy. Effusions and sera were obtained in sterile tubes and centrifuged immediately at $4^{\circ} \mathrm{C}$. Cell-free supernatants were collected and aliquots were stored frozen at $-70^{\circ} \mathrm{C}$ until use. Effusions and sera VEGF and sICAM-1 levels were measured with the commercially available VEGF and sICAM-1 ELISA kits obtained from R\&D Systems (Minneapolis, USA) according to the manufacturer's instructions.

Statistical methods. Statistical analyses were performed using by SPSS 13 for Windows. Differences in the values among the groups were determined by analysis of variance (ANOVA) procedure or nonparametric Mann-Whitney Utest and correlation analysis of different covariates was used with the Spearman rank-order correlation. In order to find the cut-off value and to evaluate and compare the performance of factors in predicting response to therapy, receiver operating characteristic (ROC) curves and Youden Index were constructed. The Kaplan-Meier method was used to 

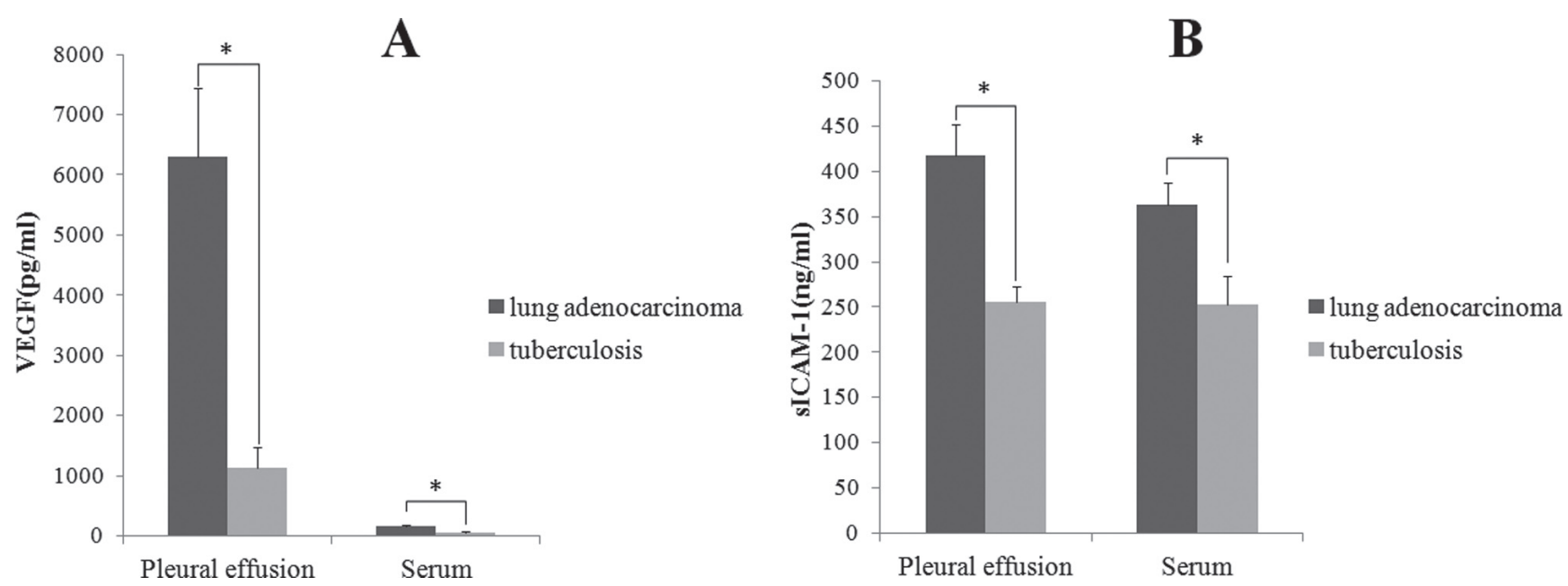

Figure 1. The levels of VEGF (A) and sICAM-1 (B) for 79 lung adenocarcinoma and 24 tuberculosis patients in serum and pleural effusion. (A) The levels of VEGF in both PE and serum were significantly higher in lung adenocarcinoma patients than that in patients with tuberculosis (for PE: $6299.28 \pm 1141.33$ and $1131.94 \pm 354.38 \mathrm{pg} / \mathrm{ml}, \mathrm{p}<0.001$; for serum: $157.34 \pm 22.64 \mathrm{pg} / \mathrm{ml}$ and $64.42 \pm 13.59 \mathrm{pg} / \mathrm{ml}, \mathrm{p}=0.018)$. (B) the levels of sICAM-1 in both PE and serum were significantly higher in lung adenocarcinoma patients than that in patients with tuberculosis patients (for PE: $418.38 \pm 34.46$ and $255.06 \pm 18.19 \mathrm{ng}$ / $\mathrm{ml}, \mathrm{p}=\mathbf{0 . 0 1 6}$; for serum: $363.88 \pm 23.11 \mathrm{ng} / \mathrm{ml}$ and $252.39 \pm 32.47 \mathrm{ng} / \mathrm{ml}, \mathrm{p}=0.013) .{ }^{*}$ indicates: difference of mean values between lung adenocarcinoma and tuberculosis groups by nonparametric Mann-Whitney $U$-test $(P<0.05)$. VEGF: vascular endothelial growth factor; sICAM-1: soluble intercellular adhesion molecule-1; PE: pleural effusions.

estimate survival and progression-free survival (PFS) distributions. Log-rank tests were used for univariate comparisons of survival and PFS end points. Cox proportional hazards regression model was used in the multivariate analysis to assess the prognostic potential of covariates adjusted for the possible confounding effects of all other factors. Progression-free survival was defined as time from diagnosis to documented progression or death, censored at the date of the last documented disease evaluation for patients without a PFS event reported. A value of $\mathrm{p}<0.05$ was considered significant.

\section{Results}

Measurement of factor levels in PE and serum. The main characteristics of patients were summarized in Table 1. For both PE and serum, there were significant differences of VEGF and sICAM-1 levels between the overall mean of lung adenocarcinoma and tuberculosis (Figure 1). The levels of VEGF in both PE and serum were significantly higher in lung adenocarcinoma patients than that in patients with tuberculosis (for PE: $6299.28 \pm 1141.33$ and $1131.94 \pm 354.38 \mathrm{pg} / \mathrm{ml}$, $\mathrm{p}<0.001$; for serum:157.34 $\pm 22.64 \mathrm{pg} / \mathrm{ml}$ and $64.42 \pm 13.59$ $\mathrm{pg} / \mathrm{ml}, \mathrm{p}=0.018)$. Similarly, the levels of sICAM-1 in both PE and serum were significantly higher in lung adenocarcinoma patients than that in patients with tuberculosis patients (for PE: $418.38 \pm 34.46$ and $255.06 \pm 18.19 \mathrm{ng} / \mathrm{ml}, \mathrm{p}=0.016$; for serum: $363.88 \pm 23.11 \mathrm{ng} / \mathrm{ml}$ and $252.39 \pm 32.47 \mathrm{ng} / \mathrm{ml}$, $\mathrm{p}=0.013$ )

We found that no correlations were observed between $\mathrm{PE}$ VEGF or sICAM-1 levels and gender, ages, smoking, stages and

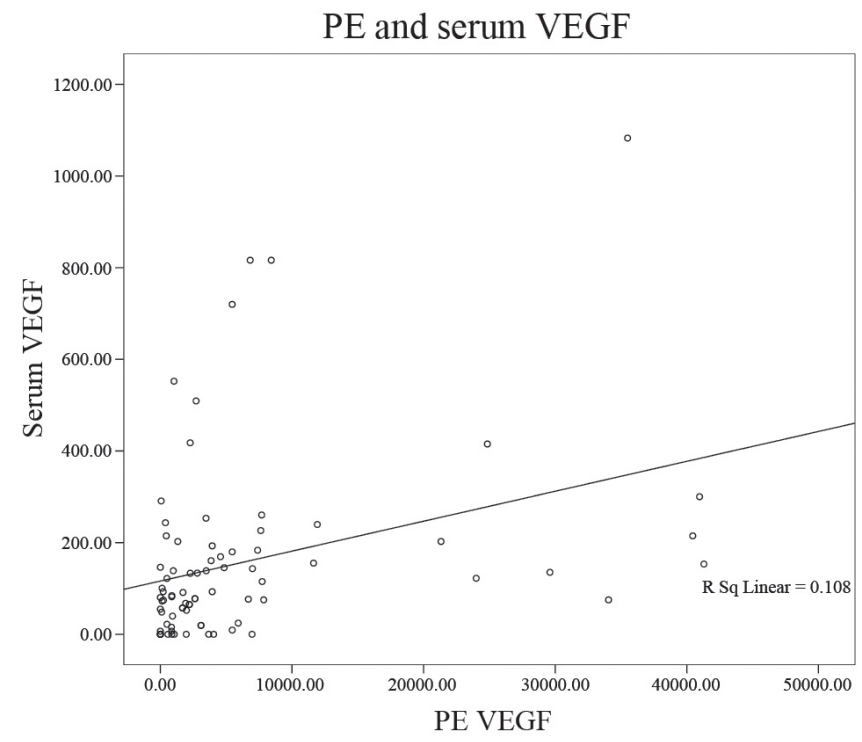

Figure 2. Correlation between VEGF in PE and serum for lung adenocarcinoma patients. When performing a Spearman rank-order correlation, we found the statistically significant correlation between VEGF values in $P E$ and serum $(R=0.499, p<0.001)$. VEGF: vascular endothelial growth factor; PE: pleural effusions.

PS. Similarly, there was no association between serum VEGF or sICAM-1 levels and these clinical characteristics.

We found also the following statistically significant correlations: VEGF values in PE and serum $(\mathrm{R}=0.499, \mathrm{p}<0.001)$ (Figure 2) and the VEGF and sICAM-1 values in serum 


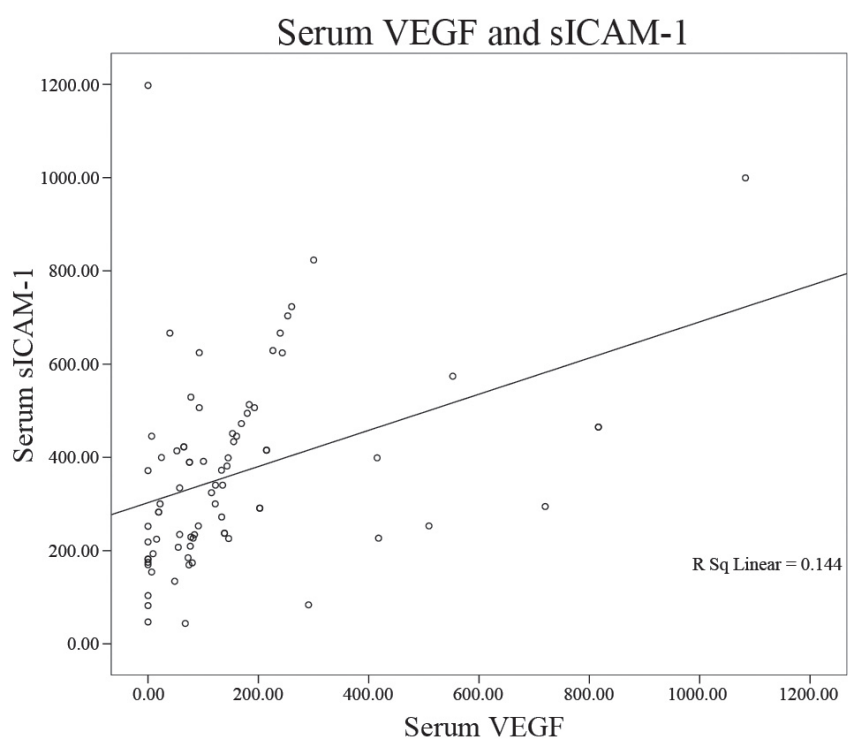

Figure 3. sICAM-1 correlated with VEGF in serum for lung adenocarcinoma patients. When performing a Spearman rank-order correlation, we found the statistically significant correlation between the VEGF and sICAM-1 values in serum $(\mathrm{R}=0.512, \mathrm{p}<0.001)$. VEGF: vascular endothelial growth factor; sICAM-1: soluble intercellular adhesion molecule-1.

$(\mathrm{R}=0.512, \mathrm{p}<0.001)$ (Figure 3). However, no association was observed between sICAM-1 values in PE and serum $(\mathrm{p}=0.453)$ and the VEGF and sICAM-1 values in PE ( $\mathrm{p}=0.753)$.

Association between PE VEGF level and MPE control. For MPE control, postero-anterior chest radiograph or ultrasonography was obtained as the baseline study and compared in every 3 weeks. Patients were divided into objective response

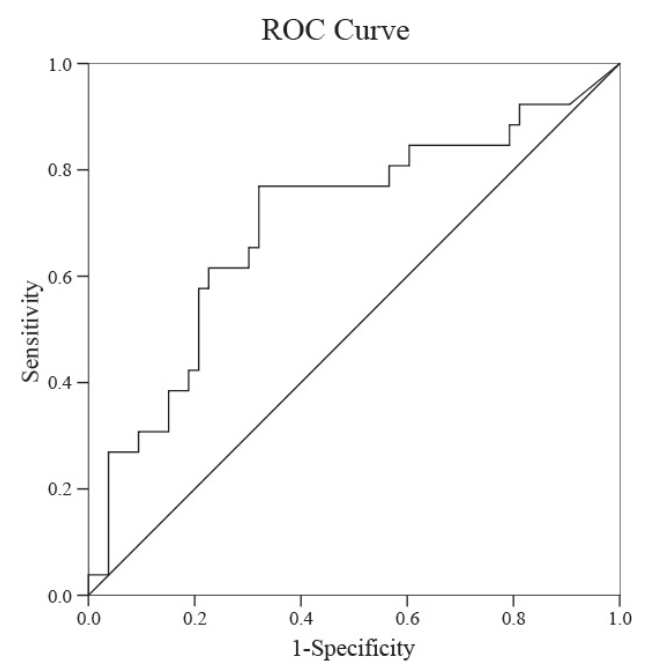

Figure 4. Receiver-operating characteristic curve analysis to assess the value of VEGF in malignant pleural effusions that predicted an Objective response to pleural effusions control. The area under the ROC curve was 0.70 ( $95 \%$ CI, 0.57-0.83).

(67\%) and failure groups (33\%). VEGF level in MPE was the only one significant factor for effusion control when comparing with other demographic and laboratory data (age, gender, smoking, stage, PS, serum VEGF, PE and serum sICAM-1) $(\mathrm{P}=0.005)$.

A receiver operating characteristic (ROC) curve analysis was carried out to assess whether PE levels of VEGF could predict an OR to MPE control (Figure 4). The area under the ROC curve was 0.70 (95\% CI (confidence interval), 0.57-0.83). The best efficacy was observed at $2760 \mathrm{pg} / \mathrm{ml}$, with a sensitivity
A

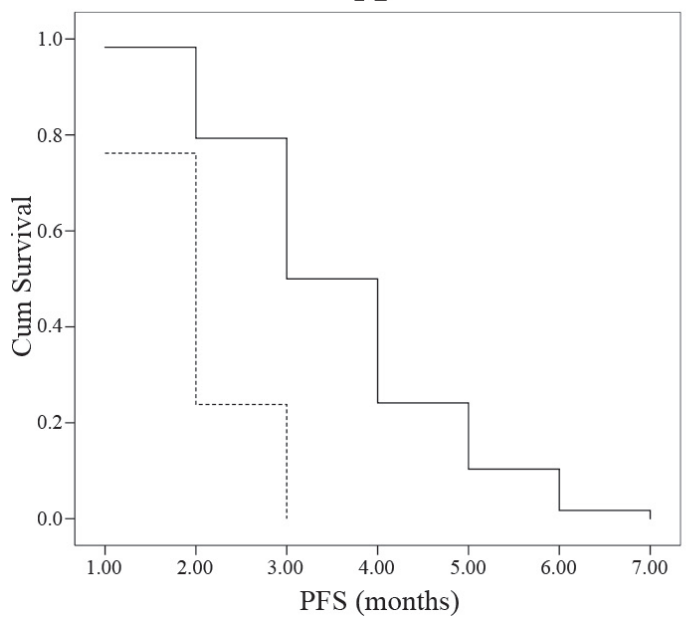

B

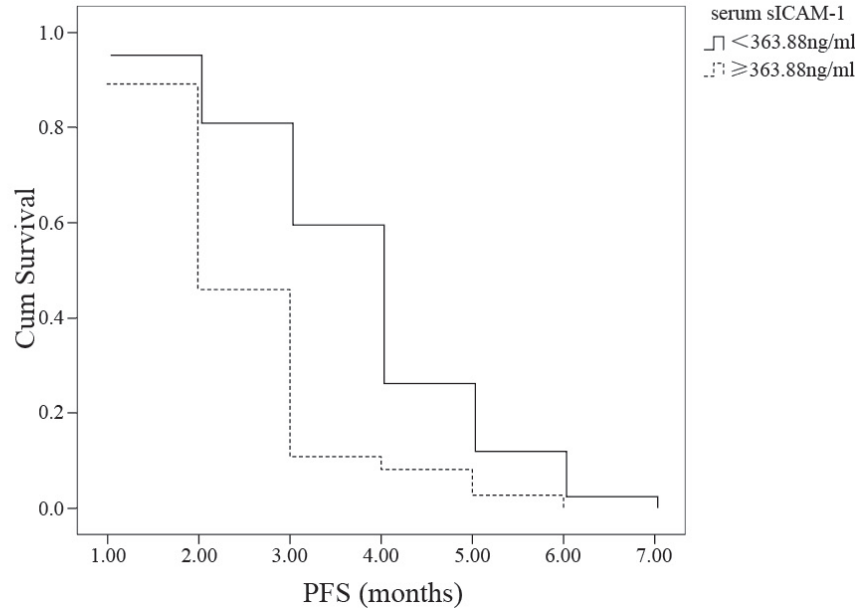

Figure 5. Kaplan-Meier survival curve of PE VEGF (A), serum sICAM-1 (B). (A) Patients with a PE VEGF level $<6299.28 \mathrm{pg} / \mathrm{ml}$ survived longer than those who had PE VEGF level $\geq 6299.28 \mathrm{pg} / \mathrm{ml}$ (3.64 months vs. 2.00 months, $\mathrm{P}<0.001)$. (B) Patients who had serum sICAM-1 $<363.88 \mathrm{ng} / \mathrm{ml}$ (the mean value of serum sICAM-1) survived longer than patients who had serum sICAM-1 $\geq 363.88 \mathrm{ng} / \mathrm{ml}(3.76$ months vs. 2.57 months, $P<0.001)$. 
of $77 \%$ and a specificity of $68 \%$ (positive predictive value, $54 \%$; negative predictive value, $86 \%$ ). Based on the ROC curve and Youden index analysis, MPE VEGF $\geq 2760 \mathrm{pg} / \mathrm{ml}$ was used as a poor indicator for effusion control as this was the value with the best efficiency in terms of sensitivity and specificity. Logistic analysis confirmed the correlation between PE VEGF and OR to MPE control (odds ratio=7.06; 95\% confidence interval, 2.40-20.78; $\mathrm{P}<0.001)$.

Survival analysis according to factor levels. For the 79 lung adenocarcinoma patients with MPE, the median PFS from the landmark date was 3 months. In the univariate analysis, a statistically significant prognostic impact on PFS from the landmark date for PS and disease stage, PE VEGF, serum sICAM-1 were observed. Patients with a PE VEGF level<6299.28 $\mathrm{pg} / \mathrm{ml}$ (the mean value of MPE VEGF) survived longer than those who had PE VEGF level $\geq 6299.28 \mathrm{pg} / \mathrm{ml}$ (3.64 months vs. 2.00 months, $\mathrm{P}<0.001)$. Patients who had serum sICAM$1<363.88 \mathrm{ng} / \mathrm{ml}$ (the mean value of serum sICAM-1) survived longer than patients who had serum sICAM-1 $\geq 363.88 \mathrm{ng} / \mathrm{ml}$ (3.76 months vs. 2.57 months, $\mathrm{P}<0.001$ ). The landmark survival curves for PE VEGF (A), serum sICAM-1 (B) were shown in Figure 5.

When a Cox multivariate regression model was applied, a statistically significant prognostic impact on PFS from the landmark date for PE VEGF and serum sICAM-1 were observed (Table 2). We found that independently prognostic roles of PE VEGF [hazard ratio (HR), 1.16; 95\% CI, 1.02-1.32], serum sICAM-1 (HR, 1.90; 95\% CI, 1.17-3.07) were confirmed. No correlations were observed in patient survival and the serum VEGF or sICAM-1 levels.

\section{Discussion}

We examined VEGF and sICAM-1 in patients with tuberculosis and MPE-associated lung adenocarcinoma and showed that the levels in PE and serums were significantly higher in patients with lung adenocarcinoma than in patients with tuberculosis. Based on our data, we found that there are good linear correlations between VEGF level in PE and in serum, and between VEGF and sICAM-1 values in serum. The results from this study support the hypothesis that $\mathrm{PE}$ VEGF $\geq 2760 \mathrm{pg} / \mathrm{ml}$ could be used as a poor indicator for MPE control. More importantly, for MPE-associated lung cancer patients, PE VEGF and serum sICAM-1 levels were considered as strong and independent predictors of PFS therapy in our multivariate analysis.

Several lines of studies agreed with our results demonstrating that VEGF levels are higher in malignant effusions from various cancers (including lung carcinomas, breast and mesotheliomas [22]) than that in benign diseases [23-26]. These results demonstrated that VEGF expression was associated with MPE. Reliable animal experiments [7] showed that the production of MPE required tumor cells to invade the pleura and to express high levels of VEGF. They found that when lung cancer cells were injected into mice, the level of VEGF expression directly correlated with the amount of MPE. Besides, the vascular permeability and pleural fluid formation induced by cancer cells can be significantly reduced when the cells are transfected with antisense VEGF $_{165}$ gene. Furthermore, other reports also demonstrated that administration of VEGF antagonists significantly reduced MPE formation in mice, all of which indicated the essential role of VEGF in MPE formation $[8,27]$. However, VEGF values in PE has limited efficacy as a diagnostic tool as values between malignant and benign effusions could be overlapped [23, 24].

Current treatment options of MPE such as indwelling pleural catheters or chemical-induced pleural fibrosis, aimed to drain or eliminate the pleural space and had little benefit for a significant number of patients $[28,29]$. For patients with $\mathrm{MPE}$, understanding the treatment efficacy and the prognostic determinants are critical to adjust treatment options. Our data suggested that PE VEGF might be a reliable marker to assess MPE control outcome and to refine prognosis of PFS for lung adenocarcinoma patients with MPE.

Table 2. Survival of patients according to several variables.

\begin{tabular}{|c|c|c|c|c|}
\hline \multirow{2}{*}{ Characteristic } & \multirow{2}{*}{$\mathrm{p}$} & \multirow{2}{*}{ HR } & \multicolumn{2}{|c|}{ 95\% CI for HR } \\
\hline & & & Lower & Upper \\
\hline Gender & 0.18 & 0.65 & 0.34 & 1.22 \\
\hline Age & 0.09 & 0.61 & 0.35 & 1.07 \\
\hline Stage & 0.75 & 0.90 & 0.47 & 1.72 \\
\hline Smoking & 0.46 & 1.27 & 0.68 & 2.40 \\
\hline ECOG PS & 0.21 & 1.31 & 0.86 & 2.00 \\
\hline MPE control & 0.68 & 0.88 & 0.48 & 1.62 \\
\hline PE VEGF & 0.02 & 1.16 & 1.02 & 1.32 \\
\hline Serum VEGF & 0.97 & 1.00 & 0.85 & 1.17 \\
\hline PE sICAM-1 & 0.53 & 0.92 & 0.69 & 1.21 \\
\hline Serum sICAM-1 & 0.01 & 1.90 & 1.17 & 3.07 \\
\hline
\end{tabular}

ECOG PS: Eastern Cooperative Oncology Group performance status; sICAM-1: soluble intercellular adhesion molecule-1; VEGF: vascular endothelial growth factor. $\mathrm{p}<0.05$ was considered significant. 
On the other hand, we found significantly elevated serum levels of VEGF in patients with MPE-associated lung adenocarcinoma compared with tuberculosis. Although the prognostic role of serum VEGF level has been supported by a strong rationale but several other studies published data $[14,30]$ including ours did not confirm this. Of course, there are some limitations in our study. Studies found that both white blood cell and platelet counts correlated with serum VEGF [31, 32]. Serum VEGF level differed depending upon the counts of platelet and white blood cells. There is some uncertainty regarding serum VEGF levels with MPE treatment efficacy and the survival significance of a high serum VEGF level. Therefore, more and large multicenter randomized studies including serum VEGF levels of patients with lung cancer are needed to further resolve this uncertainty and to increase our knowledge and experiences in separating patients.

In this study, we demonstrated that serum sICAM-1 was a independent prognostic indicator for PFS. This result is in concordance with a randomized study [14], which evaluated the combination of chemotherapy and bevacizumab and showed that serum baseline level of sICAM-1 was prognostic for survival and predictive of response to chemotherapy with or without bevacizumab. The release of sICAM-1 is modulated by several cytokines and various growth factors. One in vitro study [33] using cultured endothelial cells showed that sICAM-1 levels reflected ICAM-1 expression on these cells and endothelial cells were an important source. Although the physiological role of sICAM-1 was not completely understood, previous reports hypothesized that sICAM-1 might perform dual functions that were essential for tumor growth by inducing angiogenesis $[15,16]$ and might facilitate escape of tumor cells from immune surveillance [9]. Therefore, patients with better PFS may have lower circulation sICAM-1 levels. However, no correlations were observed in MPE treatment efficacy and serum or MPE sICAM-1. The mechanism of this phenomenon is still unclear, more in-depth studies are needed to explore the nature of this phenomenon.

In summary, our study indicates that measurement of PE VEGF as a surrogate marker prior to chemical pleurodesis can be used to assess therapeutic efficacy and predict prognosis in lung adenocarcinoma patients with MPE. Also, serum sICAM-1 is a significant negative PFS marker of patients with MPE-associated lung adenocarcinoma. We realize that the cohort size of patients in this study is small and this limits the power of multivariate analyses. Nevertheless, our data warrants validation and refinement in larger scale prospective trials in the future.

Acknowledgements: This study was supported by a grant from the Great Medical Research Program of the Nanjing Sanitary Bureau of Jiangsu Province "Personalized Therapy of Non Small Cell Lung Cancer Patients", Jiangsu Province Natural Science Foundation of China (BK2008326), and Medical Foundation for Distinguished Scholar in Jiangsu Province (RC2007113).

\section{References}

[1] LIGHT RW Clinical practice. Pleural effusion. N Engl J Med 2002; 346: 1971-1977.

[2] ANTUNES G, NEVILLE E, DUFFY J, ALI N BTS guidelines for the management of malignant pleural effusions. Thorax 2003; 58 Suppl 2: ii29-38. http: //dx.doi.org/10.1136/thorax.58. suppl 2.ii29

[3] SUGIURA S, ANDO Y, MINAMI H, ANDO M, SAKAI S et al. Prognostic value of pleural effusion in patients with nonsmall cell lung cancer. Clin Cancer Res 1997; 3: 47-50.

[4] NAITO T, SATOH H, ISHIKAWA H, YAMASHITA YT, KAMMA $\mathrm{H}$ et al. Pleural effusion as a significant prognostic factor in non-small cell lung cancer. Anticancer Res 1997; 17: 4743-4746.

[5] MACCHIARINI P, FONTANININ G, HARDIN MJ, SQUARTINI F, ANGELETTI CA Relation of neovascularisation to metastasis of non-small-cell lung cancer. Lancet 1992; 340: 145-146. http: //dx.doi.org/10.1016/0140-6736(92)93217-B

[6] FERRARA N, KERBEL RS Angiogenesis as a therapeutic target. Nature 2005; 438: 967-974. http: //dx.doi.org/10.1038/ nature 04483

[7] YANO S, SHINOHARA H, HERBST RS, KUNIYASU H, BUCANA CD et al. Production of experimental malignant pleural effusions is dependent on invasion of the pleura and expression of vascular endothelial growth factor/vascular permeability factor by human lung cancer cells. Am J Pathol 2000; 157: 1893-1903. http: //dx.doi.org/10.1016/S00029440(10)64828-6

[8] YANO S, HERBST RS, SHINOHARA H, KNIGHTON B, BUCANA CD et al. Treatment for malignant pleural effusion of human lung adenocarcinoma by inhibition of vascular endothelial growth factor receptor tyrosine kinase phosphorylation. Clin Cancer Res 2000; 6: 957-965.

[9] GEARING AJ, NEWMAN W Circulating adhesion molecules in disease. Immunol Today 1993; 14: 506-512. http: //dx.doi. org/10.1016/0167-5699(93)90267-O

[10] VANDE STOLPE A, VANDE SAAG PT Intercellular adhesion molecule-1. J Mol Med 1996; 74: 13-33. http: //dx.doi. org/10.1007/BF00202069

[11] ALEXIOU D, KARAYIANNAKIA AJ, SYRIGOS KN, ZBAR A, KREMMYDA A et al. Serum levels of E-selectin, ICAM-1 and VCAM-1 in colorectal cancer patients: correlations with clinicopathological features, patient survival and tumour surgery. Eur J Cancer 2001; 37: 2392-2397. http: //dx.doi. org/10.1016/S0959-8049(01)00318-5

[12] VIAC J, VINCENT C, PALACIO S, SCHMITT D, CLAUDY A Tumour necrosis factor (TNF) soluble receptors in malignant melanoma: correlation with soluble ICAM-1 levels. Eur J Cancer 1996; 32A: 447-449. http: //dx.doi.org/10.1016/09598049(95)00541-2

[13] NAKATA B, HORI T, SUNAMI T, OGAWA Y, YASHIRO $\mathrm{M}$ et al. Clinical significance of serum soluble intercellular adhesion molecule 1 in gastric cancer. Clin Cancer Res 2000; 6: 1175-1179.

[14] DOWLATI A, GRAY R, SANDLER AB, SCHILLER JH, JOHNSON DH Cell adhesion molecules, vascular endothelial 
growth factor, and basic fibroblast growth factor in patients with non-small cell lung cancer treated with chemotherapy with or without bevacizumab--an Eastern Cooperative Oncology Group Study. Clin Cancer Res 2008; 14: 1407-1412. http: //dx.doi.org/10.1158/1078-0432.CCR-07-1154

[15] GHO YS, KLEINMAN HK, SOSNE G Angiogenic activity of human soluble intercellular adhesion molecule-1. Cancer Res 1999; 59: 5128-5132.

[16] GHO YS, KIM PN, LI HC, ELKIN M, KLEINMAN HK Stimulation of tumor growth by human soluble intercellular adhesion molecule-1. Cancer Res 2001; 61: 4253-4257.

[17] SU WC, LAI WW, CHEN HH, HSIUE TR, CHEN CW et al. Combined intrapleural and intravenous chemotherapy, and pulmonary irradiation, for treatment of patients with lung cancer presenting with malignant pleural effusion. A pilot study. Oncology 2003; 64: 18-24. http: //dx.doi.org/10.1159/ $\underline{000066516}$

[18] NERAGI-MIANDOAB S Malignant pleural effusion, current and evolving approaches for its diagnosis and management. Lung Cancer 2006; 54: 1-9. http: //dx.doi.org/10.1016/ j.lungcan.2006.04.016

[19] HEFFNER JE Diagnosis and management of malignant pleural effusions. Respirology 2008; 13: 5-20.

[20] MUSANI AI Treatment options for malignant pleural effusion. Curr Opin Pulm Med 2009; 15: 380-387. http: //dx.doi. org/10.1097/MCP.0b013e32832c6a8a

[21] PERNG RP, CHEN YM, WU MF, CHOU KC, LIN WC et al. Phase II trial of intrapleural paclitaxel injection for non-smallcell lung cancer patients with malignant pleural effusions. Respir Med 1998; 92: 473-479. http: //dx.doi.org/10.1016/ S0954-6111(98)90294-3

[22] CHENG D, LEE YC, ROGERS JT, PERKETT EA, MOYERS JP et al. Vascular endothelial growth factor level correlates with transforming growth factor-beta isoform levels in pleural effusions. Chest 2000; 118: 1747-1753. http: //dx.doi. org/10.1378/chest.118.6.1747

[23] THICKETT DR, ARMSTRONG L, MILLAR AB Vascular endothelial growth factor (VEGF) in inflammatory and malignant pleural effusions. Thorax 1999; 54: 707-710. http: //dx.doi.org/10.1136/thx.54.8.707

[24] CHENG D, RODRIGUEZ RM, PERKETT EA, ROGERS J, BIENVENU G et al. Vascular endothelial growth factor in pleural fluid. Chest 1999; 116: 760-765. http: //dx.doi. org/10.1378/chest.116.3.760

[25] VERHEUL HM, HOEKMAN K, JORNA AS, SMIT EF, PINEDO HM Targeting vascular endothelial growth factor blockade: ascites and pleural effusion formation. Oncologist 2000; 5 Suppl 1:45-50. http: //dx.doi.org/10.1634/ theoncologist.5-suppl 1-45

[26] STRIZZI L, CATALANO A, VIANALE G, ORECCHIA S, CASALINI A et al. Vascular endothelial growth factor is an autocrine growth factor in human malignant mesothelioma. J Pathol 2001; 193: 468-475. http: //dx.doi.org/10.1002/ path.824

[27] ZEBROWSKI BK, YANO S, LIU W, SHAHEEN RM, HICKLIN DJ et al. Vascular endothelial growth factor levels and induction of permeability in malignant pleural effusions. Clin Cancer Res 1999; 5: 3364-3368.

[28] MASKELL NA, LEE YC, GLEESON FV, HEDLEY EL, PENGELLY G et al. Randomized trials describing lung inflammation after pleurodesis with talc of varying particle size. Am J Respir Crit Care Med 2004; 170: 377-382. http://dx.doi.org/10.1164/ rccm.200311-15790C

[29] BURGERS JA, KUNST PW, KOOLEN MG, WILLEMS LN, BURGERS JS et al. Pleural drainage and pleurodesis: implementation of guidelines in four hospitals. Eur Respir J 2008; 32: 1321-1327. http: //dx.doi.org/10.1183/09031936.00165607

[30] CHAKRA M, PUJOL JL, LAMY PJ, BOZONNAT MC, QUANTIN X et al. Circulating serum vascular endothelial growth factor is not a prognostic factor of non-small cell lung cancer. J Thorac Oncol 2008; 3: 1119-1126. http: //dx.doi. org/10.1097/JTO.0b013e318187464e

[31] JELKMANN W Pitfalls in the measurement of circulating vascular endothelial growth factor. Clin Chem 2001; 47: 617-623.

[32] HORMBREY E, GILLESPIE P, TURNER K, HAN C, ROBERTS A et al. A critical review of vascular endothelial growth factor (VEGF) analysis in peripheral blood: is the current literature meaningful. Clin Exp Metastasis 2002; 19: 651-663. http: //dx.doi.org/10.1023/A: 1021379811308

[33] LEEUWENBERG JF, SMEETS EF, NEEFJES JJ, SHAFFER MA CINEK $\mathrm{T}$ et al. E-selectin and intercellular adhesion molecule- 1 are released by activated human endothelial cells in vitro. Immunology 1992; 77: 543-549. 